\title{
Chapter 8 \\ The Cult of Innovation: \\ Its Myths and Rituals
}

\author{
Langdon Winner
}

Philosophers and scholars of rhetoric point to the significance of what they call "god terms," concepts that have a certain "inherent potency." God terms sweep up whole periods of history as nations and cultures strive to reach a higher state of being Richard (1953). From the late 1700s and well into the early decades of the twentieth century, for example, a prominent focus of inspiration was "Revolution," an idea that heralded sweeping social, economic, and political upheaval with the expectation of wonderful outcomes. By the same token, a fascination with "Progress" during the Enlightenment promised inevitable improvement in human knowledge and its beneficial, universal applications. Of course, a perennial favorite in the United States has long been that of "Frontier". While the specific location and meaning of the zone have changed over the years-from the geographical expanse of a great continent, to the horizons of modern science, to the space program of the 1960 geographical, to the realm of cyberspace widely celebrated in recent decades-Americans have always looked longingly toward the next "Frontier" looming over the horizon.

A popular god term today has become an object of worship in universities, think tanks, corporations, Wall Street brokerage houses, and in the dreams of our social elites. The concept is widely associated with originality, vision, inventiveness, success, wealth, fame, personal virtue, national prosperity, and cultural vitality, and features are widely understood to express the aspirations and accomplishments of twenty-first-century societies at their very best. For many people, concept has become the source of their deepest spiritual aspirations and yearnings for transcendence. In fact, it is not an exaggeration to say that today's central "god term" has begun to resemble a cult with ecstatic expectations, unquestioning loyalty, rites of veneration, and widely echoing exhortations of groupthink.

\author{
L. Winner $(\square)$ \\ Department of Science and Technology Studies, Rensselaer Polytechnic \\ Institute, Troy, NY, USA \\ e-mail: Langdon@rpi.edu \\ (C) The Author(s) 2018 \\ E. Subrahmanian et al. (eds.), Engineering a Better Future, \\ https://doi.org/10.1007/978-3-319-91134-2_8
}


The god term I have in mind is, of course, "innovation." The word derives from the Latin innovare, which means "to renew" or "to restore." In everyday speech, the word has come to mean something like: the activity of bringing new things into being that will generate sweeping renewal throughout the world. Thus, "innovation" is an inherently, overwhelmingly positive concept, a quality that may explain why so many of our contemporaries are transfixed by its very mention. In fact, it seems that a person would have to be nearly crazy to call the phenomenon into question at all. How can one criticize something that is inherently good?

To explain the astonishing popularity of The Cult of Innovation one need look no further than the aura of personal creativity that surrounds it. People imagine themselves working with new ideas, starting new enterprises, revitalizing regional economies, playing a leading part in creating what they imagine to be a lively, engaging social future. Today it seems that every person, every organization wants to be associated with "innovation."

In many ways, the study and promotion of innovation have become a dynamic growth industry. There are now research centers, university departments, academic journals, book series, and the like engaged in an intensive quest to find the right recipe, the right mix of ingredients, exactly the right alchemical formula, to make it all happen. In deliberations about business strategy, public policy, and personal career planning, questions of this kind have become primary concerns. Which kinds of corporate culture, which varieties of university education, which programs of government support, and which social and psychological traits are the ones best suited to fostering innovation? Is advanced research and development the key? What varieties of management are most helpful? Isn't new technology the true fountainhead? Or does the magic arise from interdisciplinary or cross-cultural teams? What about the role of the arts and humanities in the alchemical mix? And what role should government play in the search for the new philosopher's stone?

Recommendations for promising recipes and methods often begin in Silicon Valley, Seattle, or Cambridge and move on to and recommend ingredients and likely to work in one's own corner of the world. We often hear that a particular firm, industry or whole nation has flourished because it found a distinctive path to the promised land. In contrast, we are sternly advised that conventional practices or policies - e.g., taxation or attempts at government steering and planning-are bound to be destructive because they tend to put a brake upon innovation, a most despicable thing to do.

I am certainly not immune to this way of thinking and talking. I now teach in a university undergraduate program Design, Innovation and Society, an outgrowth of an earlier cross-disciplinary program in Product Design and Innovation. We have our own favorite methods, recipes, and ways of motivating bright young women and men. Indeed, many of my own questions here stem from a simple desire to understand: What is this wonderful "innovation" process we all keep chattering about? 


\subsection{Gadgetology}

At the level of popular culture, one feature of the Cult of Innovation I find fascinating is its veneration of the gadget. For many people in young people in colleges and universities, in Silicon Valley firms, and the like, the effective goal appears to be the search for the next iPod, iPad, or ingenious "app" for one's smartphone. Among those, I regularly talk with about such matters, if one asks- "What's the goal of the innovation you're working on?"- a common answer seems to be, "Well, it's a hand held digital device, a lot like an iPhone only different." "Or it's a smartphone app that helps people who want an easier way to...".

A while back I did an Internet search for lists of the most notable innovations of 2015. ${ }^{1}$ Here are some of hundreds of notable examples from newspapers, magazines, and websites:

The HTC Vive: - a virtual reality headset with a pair of 1080 pixel viewing screens;

The Microsoft HoloLens - a camera equipped headset with augmented virtual reality capabilities for the gaming and educational markets;

Sony Smart Btrainer - earpieces that play music, monitor one's heartbeat and track data from one's daily exercise;

BB-8 A Star - a rolling Star Wars droid you can own;

6Sensor Lab Nima - a portable gluten sniffer (key breakthrough in America's war on gluten).

Not all of the "innovative" products were electronic in character. For example, the Nike Zoom Soldier Flyease 8 is an athletic shoe one can tie with one hand. What the other hand might be doing is not specified in the company's advertisements.

At the top of Time Magazine's list of the most notable inventions of the year was the Hoverboard Scooter. Shortly after it received this award, alas, the reputation of the Hoverboard collapsed when risks of fire and explosion caused by battery failure, forcing the recall of a reported half million of these nifty devices.

It is not always clever stand-alone gadgets that receive the applause. Some of the more fascinating innovations emerge as whole genres or networks, elaborate projects with a great many applications. "The Internet of Things" is an ongoing promotion of this kind. Even that, I am advised, may not be sensational enough. A friend who works in a firm devoted to innovative design tells me that the latest wrinkle is "The Internet of Caring Things." In a society that seems to care about us less and less, we'll have networked things that care more and more.

A notable example is Cuptime, a plastic cup that "connects wirelessly with a cell phone, allowing consumers to monitor their water intake." Obviously, this will be a

\footnotetext{
${ }^{1}$ Among the websites I visited were these: "The 25 Best Inventions of 2015," TIME Staff. http:// time.com/4115398/best-inventions-2015/. "The 100 Greatest Innovations of 2015," Popular Science Staff, October 23, 2015. http://www.popsci.com/100-greatest-innovations-2015.
} 
godsend that will greatly improve the quality of everyday life. ${ }^{2}$ Of course, one could also just watch how much they are drinking. But that wouldn't be especially "innovative," would it?

Yes, it is impressive to see such ingenuity and devotion lavished upon the marvelous products and smartphone applications flooding the market. Yet one has to wonder, do we find ourselves living on the Planet of the Apps?

\subsection{Elitism}

Closely associated with Gadgetology is a penchant for elitism-inquiries whose likely outcomes are geared to the world's wealthy and already best served: well-to-do consumers and global firms. Because this is a signature feature of prevailing practice and because some of those who aspire to become "innovative" also have more noble goals in mind, there are now scattered efforts to disentangle high tech creativity from its emphasis upon the needs of the wealthy few. Implicit misgivings about elitism can be seen in creation of centers and programs that find it necessary to modify the names for what they are doing. The Center for Social Innovation at Stanford University wants us to understand that it "envisions a networked community of leaders... to build a more just, sustainable and prosperous world." 3 There are now several centers for "social innovation" around the U.S.A., ones that shift the focus of their inquiries beyond mere money and marketing. Other initiatives - indeed some favored by my own colleagues - are eager to point out that what they are doing actually is "good" or "ethical" innovation-technical and/ or policy change aimed at the world's poor people or some other admirable causes. As laudable as such projects may be, they also tip the hand of "innovation" manias in common practice.

\subsection{Benign Innovation}

Despite these misgivings, it's clear that there are many of the kinds of creativity called "innovation" that truly are well worth celebrating. One could mention contributions that change, enliven, enrich, and extend long-standing and practices in the crafts, medicine, technology, music, and countless other fields of human endeavor.

\footnotetext{
${ }^{2}$ Internet of Caring Things, April 2014, Trend Briefing. http://trendwatching.com/trends/internetof-caring-things/.

${ }^{3}$ Center for Social Innovation, Stanford Graduate School of Business. https://www.gsb.stanford. edu/faculty-research/centers-initiatives/csi.
} 
At the top of my own list would be the astonishing career of Miles Davis, a great innovator in twentieth-century jazz. Beginning in the 1940s as a rather ordinary player in the style of bebop, Miles soon moved on to a more smooth, mellow harmonically complex style known as cool jazz. During the decades that followed, he again and again changed his approach to music, initiating or contributing to hard bop, orchestral jazz, jazz/rock fusion, hip-hop, and other styles.

Miles never rested on his laurels. At the pinnacle of success of one pioneering style, he abruptly would drop it and move on to something else. Thus, he left to the history of jazz a long sequence of stunning, successful, highly generative innovations. Yes, he intervened to interrupt and redirect the ways the music was conceived and played. But he also connected and uplifted, steps in the process often overlooked or even strongly disparaged these days.

Another creative soul of this kind, working in a much different domain, is Alice Waters, restaurateur and advocate of new ways of growing, cooking, and eating foods in the U.S. and around the world. Beginning in 1970s with her restaurant Chez Panisse in Berkeley, Waters took aim at the prevailing culinary practices of the time-overcooking, too much gravy, too much grease, etc.- and introduced methods that emphasize fresh, locally grown, organic ingredients, carefully prepared in a direct, tasty manner, a way of cooking that came to be known as the California Cuisine. Eventually, her "innovations" became a model for transformations in restaurant and home cooking that swept the country (and much of the world) during the decades that followed.

To my way of thinking activities and projects that modify and renew traditions and instruments of practice, might be called graceful or benign innovation. What characterizes them, in my view, is that they usually, deeply respect what came before and yet chart new, challenging, fruitful possibilities. The old traditions are not trashed, but modified, gracefully unfolding into something new.

\subsection{Smash and Grab}

Of course, in today's understandings of technological, financial, and corporate strategy, it is not the model of benign innovation that is the object of fascination and advocacy. Instead, the models praised are ones that involve deliberate social, cultural, and material violence — often described as "destruction" or "disruption." Far from respecting and building upon a tradition of tools and methods, the recommendation is to plunge ahead, discrediting, smashing up rapidly replacing what came before, usually with a narrow set of motives in mind-corporate profit and market capture.

While the term innovation has long had a long history in European languages, it is possible to date its emergence as a key concept in thinking about technology policy to the middle twentieth century, especially in the writings of the Austrian thinker Joseph Schumpeter, who eventually taught economics at Harvard. Pondering the dynamics of modern capitalism and in particular the ways in which 
new industries replace old ones and new product's replace functionally similar products of earlier times, Schumpeter proposed the notion of "creative destruction." He wrote, "The fundamental impulse that sets and keeps the capitalist engine in motion comes from the new consumers' goods, the new methods of production or transportation, the new markets, the new forms of industrial organization that capitalist enterprise creates." Schumpeter emphasized the dynamics of a "process of industrial mutation ... - that incessantly revolutionizes the economic structure from within, incessantly destroying the old one, incessantly creating a new one. This process of Creative Destruction is the essential fact about capitalism" (Joseph 1950).

Although Schumpeter's term seemed new and catchy at time, an entirely similar idea had been around for a long while. In 1848, Karl Marx and Friedrich Engels observed that "The bourgeoisie cannot exist without constantly revolutionizing the instruments of production. ... All that is solid melts into air, all that is holy is profaned."

In recent years, the idea that change involves deliberate attack redefined under the rubric, "Disruptive Innovation," a theory and strategy widely promoted in business schools, Silicon Valley, and on Wall Street. Prominent spokesman for this tactic is Clayton Christensen of the Harvard Business School. Christensen's method is to locate existing sources of value contained within existing fields of endeavor-communications, transportation, health care, hotels, education, etc., and fundamentally restructure them with a disruptive innovation of some kind or another. If one can crack open the existing social container of economic value and strongly reconfigure its flows and contents, recapitalize its terrain, then the rewards will come pouring out, captured as profits for some new business enterprise (Clayton 1997).

Christensen's conviction is that, in fact, such disruptions are inevitable given the continuing emergence of new forms of hardware and software that eventually and challenge and destroy the status quo in just about any form of organized social activity one can mention. Disruptive innovations occur when a new product or idea "transforms an existing market or sector by introducing simplicity, convenience, accessibility, and affordability where complication and high cost are the status quo." Paradigmatic in his view was the replacement of the mainframe and min computers of earlier generations by the high powered "personal computers" of the 1980s and since.

Christensen and his followers now apply this way of thinking in many areas of business and social life, including education. His book on that topic, Disrupting Class: How Disruptive Innovation Will Change the Way the World Learns, makes it clear that innovation in the schools must be aggressive and forceful. At the book's conclusion he advises his readers:

\footnotetext{
${ }^{4}$ Marx, K., \& Engles, F. Manifesto of the communist party, Part I. https://www.marxists.org/ archive/marx/works/download/pdf/Manifesto.pdf.
} 
The tools of power and separation, though they seem foreign to leaders who have been schooled in consensus, are the key pieces of the puzzle of education reform. As you face budget crises and difficulty finding teachers, don't solve the problems by doing less in the existing system. Solve it by facilitating disruption. (Clayton 2008)

It's interesting that he openly embraces the classic military and political strategy of divide and conquer. As a program of restructuring and possible improvement for long-standing institutions, their commitments, practices, and practitioners, Christensen's worldview revises an old American maxim: "If it ain't broke, don't fix it." That now becomes, "If it ain't broke, by all means break it!" As if to turn the classic Hippocratic Oath for medical and professional ethics on its head, fashionable maxim seems to be: "First do some harm!"5

\subsection{Jewel in the Crown}

Today's ideas of "innovation" inherit the optimistic aura of a god term noted earlier - the idea of "Progress," a notion that long expressed the highest aspirations of modernity, hopes that looked to continuing expansion of scientific knowledge, embodied in technological advance, leading to inevitable improvement in nutrition, health, mobility, and other kinds of material well-being along with general improvement in social, moral, and political conditions. An early statement of this dream was offered by Rene Descartes in his Discourse on Method. "I perceived it to be possible to arrive at knowledge highly useful in life...to discover a practical, by means of which, knowing the force and action of fire, water, air the stars, the heavens, and all the other bodies that surround us, as distinctly as we know the various crafts of our artisans, we might also apply them in the same way to all the uses to which they are adapted, and thus render ourselves the lords and possessors of nature." 6

While twenty-first century hopes for "innovation" echo beliefs of this kind, there some crucial differences. In everyday parlance "innovation" is usually regarded as a matter of limited application often geared to market-centered benefits. A product or idea is useful, accessible, flexible, visually appealing, and lower cost than the available alternatives. It helps a business or organization vanquish the competition and capture savings and profits. But a central feature of the classic idea of progress - that there is an inevitable, universal tendency toward improvement in living conditions for all of humanity - that is no longer part of the program. Indeed, in today's fashions of thinking and talking, "innovation" is perhaps best seen the jewel in the crown of neoliberalism, the ruling ideology of our time, a pungent worldview

\footnotetext{
${ }^{5}$ A recent survey of the sources of actual innovation finds that "destruction" is not as productive as its advocates claim. Daniel Garcia-Macia et al. How destructive is innovation? Working Paper 22953, National Bureau of Economic Research, December 2016.

${ }^{6}$ Descartes, R. Discourse on method, part IV.
} 
that promotes economic liberalization, privatization, "free trade," open markets, deregulation, privatization of formerly public institutions, and cuts in government spending (especially for social programs) in order to enhance the role of the private sector in the economy and society as a whole. From this standpoint, market-based approaches are generally thought to be superior because they foster a spirit of innovation by those who hope to profit from their success. The core belief is that the world will improve incrementally by the proliferation of clever innovations that succeed in the global marketplace. Hence, we can celebrate the renunciation of any widely shared project to realize the common good because improvement will be achieved in other ways. And we can welcome the destruction of institutional and material frameworks that previously sought to realize social, economic, and political well-being as a project within the public sphere. Now secured by the efforts of clever people in their private pursuits, an enhanced, often upgraded world pours steadily from the laboratories and corporations. This is how things get better! (Eagleton-Pierce 2016).

The widely heralded features of "creative destruction" and "disruptive innovation" play a role in the episodes of "shock doctrine" described in the Naomi Klein's analysis of the excesses of neoliberal policies around the globe (Klein 2006). Klein argues that when an earthquake, tsunami, war, revolution, coup d'etat, or financial crash upsets the existing order of things, often the event is seized upon as an opportunity for radical, right-wing, market-centered restructuring. In the several case histories she analyzes, one finds deliberate, well-planned programs of shock doctrine, almost always to the benefit of political oligarchs, autocrats, billionaires, and global firms. By the same token, policies of this kind are direct alternatives to egalitarian strategies that seek "the common good" within the societies affected. Policies of neoliberalism - outsourcing, privatization, anti-unionism, deregulation in banking and environmental protection, dismantling of public services, pressures to maintain low wages, the imposition of a mountain of debt on college students, and similar measures are now widely recognized to have contributed to the steady erosion of the incomes and life prospects for the middle class and working people in the U.S.A. Thus, glowing hopes for "innovation" are all that remains as more conventional doors to social betterment are slamming shut.

\subsection{Expecting Miracles}

Within political discussions of the great issues facing humanity at present-world poverty, inequality, energy crisis, resource depletion, environmental ills, global climate change, etc. - the idea of innovation plays a crucial role. Many observers

are inclined to say, "If only we were innovative enough, these problems would likely be solved."

Is this confidence warranted?

Will we innovate ourselves out of the rapidly widening gaps of inequality in wealth and income that afflict many world societies? 
Will we innovate ourselves away from the utter dependence upon fossil fuels upon which modern civilization depends?

Will we innovate in ways that eliminate the rapidly moving threat that global climate crash poses to countless biological species, including our own?

A notable example of the widespread tendency to insert the idea of "innovation" when confronted with a world-historical crisis comes from the statements and practical commitments of Microsoft mogul Bill Gates. His vision of this strategy was briefly in a 2010 TED Talk on global warming, "Innovating to Zero.",

"We need solutions," Gates exclaimed, "either one or several that have unbelievable scale and unbelievable reliability....".

"These breakthroughs, we need to move those at full speed, and we can measure that in terms of companies, pilot projects, regulatory things that have been changed." Gates mused optimistically that if the expected technological miracles all happened as expected, the world could reach zero carbon emissions within the decades ahead.

To his credit, Gates has recently pledged $\$ 1$ billion of his own wealth and organized a group of billionaire friends to support research and development on clean energy. Along with its anticipated role in combatting climate change, the project would also address several other global problems. "If we create the right environment for innovation," Gates proclaimed at the project's debut, "we can accelerate the pace of progress, develop and deploy new solutions, and eventually provide everyone with reliable, affordable energy that is carbon free. We can avoid the worst climate change scenarios while also lifting people out of poverty, growing food more efficiently, and saving lives by reducing pollution." ${ }^{8}$ Among the specific steps needed in his view are increased government and private funding for research on clean energy solutions accompanied by the creation of economic incentives that can speed such "solutions" into the market.

\subsection{Procrastovation}

One can compare the enthusiasm Mr. Gates and other techno-optimists of our time with reports on climate change and its consequences that issue from scientific organizations published in a steady stream these days. Conveying an increasing sense of urgency, many scientists and policymakers insist that the situation is already spinning out of control and that the time to cut carbon emissions is very short. Hence, international agreements reached in 2015 at the COP2 1 climate change conference in Paris established a limit of $2{ }^{\circ} \mathrm{C}$ increase by the end of the

\footnotetext{
${ }^{7}$ Bill Gates, "Innovating to zero!" TED2010.

${ }^{8}$ Davenport, C. Bill Gates expected to create billion-dollar fund for clean energy. New York Times, November 27, 2015. http://www.nytimes.com/2015/11/28/us/politics/bill-gates-expected-tocreate-billion-dollar-fund-for-clean-energy.html?_r=0.
} 
century with an urgent goal of no more than 1.5 degrees over preindustrial levels. While these targets are a strong step forward when compared to earlier negotiations, for many observers they seem too little, too late. As Professor Stefan Rahmstorf of the Postdam Institute for Climate Impact Research warns, "These [climate change records] are very worrying signs and I think it shows we are on a crash course with the Paris targets unless we change course very, very fast. I hope people realize that global warming is not something down the road, but it is here now and affecting us now." 9

As regards measures that could reduce carbon emissions, there are a number straightforward, readily alternatives in social policy that are often proposed: instituting stiff carbon taxes, drastically reducing energy use in housing and everyday patterns of consumer behavior, lowering automobile speed limits, drastically reducing airline travel, etc. The tendency to look toward expected technological miracles in the longer term rather than immediately deploy mundane alternatives is perhaps the primary contribution of the Cult of Innovation to today's spiraling climate crisis. A good name for this deeply entrenched obsession would be "Procrastovation"-putting off until tomorrow the practical steps that could offer substantial improvement right away.

In that light, an important but seldom asked question is this: Today's cherished rituals of Innovation/Procrastovation are an alternative to what?

While there are many conceivable answers, a good beginning would be to recognize the need for widespread democratic deliberation, inquiry, debate, and formation of a strong resolve to tackle serious problems that face the global community. A strategy of this kind was enthusiastically launched at the U.N. Rio Summit of 1992 and produced, among other accomplishments, an emphasis upon the challenge of balancing economic prosperity with measures to ensure long-term environmental well-being. Along similar lines, it seems sensible to reinvigorate widely known varieties of public planning, including plans for the deployment of technologies and institutional programs that already exist and likely to bring fruitful results.

If, as many climate scientists now insist, there is only a decade or two to achieve substantial reductions in the carbon emissions before the situation turns truly critical, can we afford to procrastovate any longer?

In fact, within the international community of those looking for effective remedies to address climate change, there is now a heated debate about pathways of deployment for existing problem-solving methods in contrast to exotic dreams for techno-magical devices anticipated on the distant horizon. Many have begun to identify the obsession with "innovation" as the last great excuse that prevents societies from taking the bold, quick, decisive steps needed to curtail the

\footnotetext{
${ }^{9}$ Quoted in Damian Carrington. Shattered records show climate change is an emergency today scientists warn. The Guardian, June 17, 2016. https://www.theguardian.com/environment/2016/ jun/17/shattered-records-climate-change-emergency-today-scientists-warn.
} 
civilizational bad habits that have placed Earth's biosphere in jeopardy. ${ }^{10}$ As entrepreneur Jigar Shah observes, "Solar and wind are winning around the world not because of fundamental technological breakthroughs, but instead because after 30 years the banking sector is finally comfortable scaling up their use... I am not against innovation, but we don't need to be telling people that we need it to reach the 2 degrees milestone being talked about in Paris. What we need is deployment" (Shah 2015).

Despite warnings of this kind, a stubborn preference for "innovation" over more conventional readily available approaches to problem-solving is common among those who imagine themselves to be the sole saving remnant-philanthropic visionaries guarding humanity's future. Perhaps tendencies of this kind that such tendencies to stem from deeply ingrained occupational habits, ones that have worked so well in those in the world of business. For celebrities in Silicon Valley and other high tech meccas, "innovation" is what they know how to do, where they've been so successful. But as evidence of global poverty, inequality, energy crisis, and collapse of Earth's climate system become more difficult to deny, our technical elites often revert to a kneejerk reflex, seeing such troubles an exciting opportunity for venture capital, a chance to launch a bunch of cool new "startups."

\subsection{Homilies}

For the followers of powerful "god terms" and their inspiring worldviews, a set of moral lessons is included as part of the package. Its standards identify the truly worthy persons as compared to those found lacking or even obstructive when it comes to achieving the dream. Thus, for those mobilized by the myth of "Revolution" and imaginaries of "Frontier" it made perfect sense to identify the chosen people, those expected to carry the banner bravely into the future, as against the benighted souls who stood in way of positive change, groups who needed to be removed, exterminated or harshly dealt with in some way or another.

Among devotees of the beliefs and rituals discussed here, a pungent set of judgments assigns praise and blame. As long as one is being "innovative," things are bound moving on the right path and likely headed toward wonderful outcomes. "Just do your best to become one of the creative elect and the blessings will surely shower down upon you." In my experience, much of university teaching now generates homilies of that kind, reassurance for young people who spend huge sums of money in hopes of joining the clever, rich, and powerful.

Even more relevant to most of the world's seven billion people, however, the moral philosophy of innovation also contains a pungent (but often unspoken)

\footnotetext{
${ }^{10} \mathrm{Gaddy}, \mathrm{B}$. The innovation vs. deployment debate in energy: How did it get so heated? https:// www.greentechmedia.com/articles/read/revisiting-the-innovation-versus-deployment-debatewhere-did-it-come-from.
} 
message of blame. "If you are not among the 'innovative' souls actively seeking to disrupt and reconfigure long-standing practices, enterprises, tools, and institutions, then you have only yourself to blame for the dreary fate that surely awaits you in the years ahead. You had your chance and you blew it! And please don't come to us asking for any sympathy or handouts. That's old school thinking - ideas about the common good, a just society and all that. We've moved beyond those dreary, outmoded concerns." One does not have to go to very many Silicon Valley workshops or seminars by smooth talking business school gurus to receive the uplifting message: "Innovate or Die! Innovate or Perish!"

In sum, "innovation" appears magically before our eyes - the jewel in the crown of neoliberalism, a fabulous gift promised those who doggedly pursue the economic and technological obsessions of the early twenty-first century. Within this aura The Cult of Innovation steadily expands - a throng of true believers engaged in ceaseless adoration of a beloved but ultimately tawdry (perhaps even deadly) treasure.

\section{References}

A recent survey of the sources of actual innovation finds that "destruction" is not as productive as its advocates claim. Daniel Garcia-Macia et al. How destructive is innovation? Working Paper 22953, National Bureau of Economic Research, December 2016.

Among the websites I visited were these: “The 25 Best Inventions of 2015," TIME Staff. http:// time.com/4115398/best-inventions-2015/. "The 100 Greatest Innovations of 2015," Popular Science Staff, October 23, 2015. http://www.popsci.com/100-greatest-innovations-2015.

Center for Social Innovation, Stanford Graduate School of Business. https://www.gsb.stanford. edu/faculty-research/centers-initiatives/csi.

Clayton, C. M. (1997). The innovator's dilemma: When new technologies cause great firms to fail. Cambridge: MA, Harvard Business School Press.

Descartes, R. Discourse on method, part IV.

Clayton, C. M. (2008). Disrupting class: How disruptive innovation will change the way the world learns (pp. 226-227). New York: McGraw Hill.

Davenport, C. Bill Gates expected to create billion-dollar fund for clean energy. New York Times, November 27, 2015. http://www.nytimes.com/2015/11/28/us/politics/bill-gates-expected-tocreate-billion-dollar-fund-for-clean-energy.html?_r=0.

Gaddy, B. The innovation vs. deployment debate in energy: How did it get so heated?. https:// www.greentechmedia.com/articles/read/revisiting-the-innovation-versus-deployment-debatewhere-did-it-come-from.

Eagleton-Pierce, M. (2016). Neoliberalism: The key concepts. New York: Routledge.

Gates, B. Innovating to zero! TED2010. https://www.ted.com/talks/bill_gates.

Internet of Caring Things, April 2014, Trend Briefing. http://trendwatching.com/trends/internet-ofcaring-things/.

Joseph, A. S. (1950). Capitalism, socialism and democracy (3rd ed., pp. 81-82). New York, N.Y.: Harper Torchbooks (1962).

Marx, K., \& Engles, F. Manifesto of the communist party, Part I. https://www.marxists.org/ archive/marx/works/download/pdf/Manifesto.pdf.

Klein, Naomi. (2006). The shock doctrine: The rise of disaster capitalism. New York: Metropolitan Books. 
Quoted in Damian Carrington. Shattered records show climate change is an emergency today scientists warn. The Guardian, June 17, 2016. https://www.theguardian.com/environment/ 2016/jun/17/shattered-records-climate-change-emergency-today-scientists-warn.

Richard, M. (1953). Weaver, the ethics of rhetoric. Davis, CA: Hermagoras Press.

Shah, J. (2015). Jigar shah to Bill Gates: We already have the technology to solve climate change. ImpactAlpha, December 2, 2015. http://impactalpha.com/dear-bill-gates-we-already-have-thetechnology-to-solve-climate-change/.

Open Access This chapter is licensed under the terms of the Creative Commons Attribution 4.0 International License (http://creativecommons.org/licenses/by/4.0/), which permits use, sharing, adaptation, distribution and reproduction in any medium or format, as long as you give appropriate credit to the original author(s) and the source, provide a link to the Creative Commons license and indicate if changes were made.

The images or other third party material in this chapter are included in the chapter's Creative Commons license, unless indicated otherwise in a credit line to the material. If material is not included in the chapter's Creative Commons license and your intended use is not permitted by statutory regulation or exceeds the permitted use, you will need to obtain permission directly from the copyright holder.

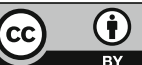

